\title{
Ensino-Aprendizagem da Língua Materna e Ideologia: um Estudo sobre as Concepções e a Prática Pedagógica de Alfabetizadores de Escolas Públicas do Recife*
}

\section{Maria Cristina Hennes Sampaio \\ Universidade Federal da Paraíba (UFPB) \\ Rosilda Arruda Ferreira \\ Universidade Federal de Pernambuco (UFPE)}

Aborda a maneira como a prática pedagógica de ensino-aprendizagem da língua materna vem sendo conduzida na escola pública, considerandose a diversidade sociolinguística de sua clientela. Estudou-se uma amostra de 75 professores de $1^{a}$ série do $1^{\circ}$ grau da rede de escolas públicas de Recife e estabeleceu-se uma tipologia envolvendo padrões conceituais e ações de ensino-aprendizagem de língua materna, correlacionadas a diversas variáveis sociais. O processo foi também investigado através de um estudo de redes adaptado deMilroy (1980). Foram observadas cinco categorias conceituais que apresentam diferenças e que se inserem em apenas uma única categoria de ação pedagógica. Concluiu-se que a maioria dos professores apresenta um perfil cujos traços conceituais estão voltados para os valores lingiiísticoculturais das classes dominantes. Da correlação entre as cinco categorias conceituais e uma única categoria de ação, concluiu-se que falta articulação entre teoria e prática, particularmente no que se refere às categorias conceituais $T V e V$, que se diferenciam das demais por apresentarem traços de identificação para com os valores linguístico-culturais das classes populares. Conclui-se, também, que a inserção do professor na comunidade de classe popular onde trabalha, e a sua vinculação a essa classe não

- Esta pesquisa contou com a colaboração de Eugênia de Ermínia de Aguiar Oliveira e Marilda Ferreira Chaves, alunas-bolsistas do CNPq. 
apresentam uma relação direta com uma aproximação ou um afastamento dos valores lingtiístico-culturais das classes dominantes ou populares. Os resultados possibilitaram a compreensão da relação dialéíica do signo enquanto efeito das estruturas sociais, bem como em que medida a identidade social, modelada ou parcialmente modelada pela ideologia dominante, condicionou as concepções e a ação pedagógica dos professores. Além disso, a contraposição de ambas possibilitou a identificação da dificuldade de artiadação entre teoria e prática e uma reflexão sobre as possibilidades de sua superação.

Uma preocupação crescente que vem sendo manifestada com mais evidência pelo número significativo de trabalhos, mesas-redondas e conferências apresentadas pela comunidade científica, nas áreas de Educação, Linguística e Letras, diz respeito a temas relacionados ao ensinoaprendizagem da língua portuguesa, suscitando o reconhecimento da necessidade de uma discussão ampla em torno do estabelecimento de uma política para o seu ensino no Brasil.

A questão é complexa, pois envolve uma reflexão não apenas no nível teórico-prático acerca do ensino-aprendizagem da língua materna (LM), da caracterização das diversas clientelas, mas também, e fundamentalmente, acerca da formação e da prática do professor no contexto de uma sociedade global, que tem por base relações de classe, determinadas historicamente, onde se delineiam e se afirmam as ideologias dominantes e as contraideologias.

Nesta perspectiva, o objetivo de nosso estudo foi o de traçar o perfil de uma amostra de professores alfabetizadores da rede de ensino público da cidade do Recife quanto às suas concepções de língua materna, de seu ensino e aprendizagem, tentando verificar até que ponto essas concepções influenciavam suas práticas pedagógicas.

Para que pudéssemos melhor compreender o problema, fez-se necessário, antes de tudo, explicitar a concepção de alfabetização que se 
faz presente na escola e que orienta toda uma prática pedagógica. Neste particular, considerando a amplitude de abordagens envolvidas no processo de alfabetização, desde aspectos político-pedagógicos, cognitivos, linguísticos e sociolinguísticos, nos detivemos nestes dois últimos, onde se situa o problema do ensino-aprendizagem da língua portuguesa como LM.

É quase um consenso, entre alfabetizadores e técnicos do ensino público, que a $1^{\mathrm{a}}$ série do $1^{\mathrm{o}}$ grau, ou seja, a alfabetização, constitui-se a série inicial à aprendizagem da "leitura" e da "escrita". Leitura e escrita entendidas não como um processo de aprendizagem de um código linguístico em sua dupla articulação significante/significado, na perspectiva da aquisição de uma competência linguística, oral e escrita, e de variedades linguísticas, mas como uma aprendizagem mecanicista, de um mero código gráfico, onde se processam a codificação de sons e a decodifícação em grafismos.

Dessa forma, dissociar a aquisição da leitura e da escrita da aprendizagem da língua é tornar sem sentido o próprio ato de ler e escrever. Conforme já demonstrado em diversos estudos (Sampaio, Spinillo e Chaves, 1990; Sampaio e Spinillo, 1986; Rego, 1984; Halliday, 1973), a competência linguística, oral e escrita, não parece ser adquirida automaticamente, mas precisa ser desenvolvida nos indivíduos — trabalho que pode e deve ser iniciado a partir da pré-escola, considerando-se, evidentemente, o nível de desenvolvimento cognitivo e linguístico das crianças.

Outro problema que se coloca, particularmente na escola pública, concerne ao fato desta privilegiar basicamente os padrões linguísticos e culturais das classes socialmente privilegiadas, ignorando os padrões das classes populares que, contraditoriamente, se constituem na clientela predominante dessa mesma escola.

Nesta perspectiva, estudos de Sampaio e Spinillo (1986) demonstraram que muitas das dificuldades de aprendizagem, no processo de alfabetização, são decorrentes das diferenças entre a variedade linguística falada pelas 
crianças e a ensinada na escola, sugerindo possibilidades de sua superação mediante o desenvolvimento de habilidades de reflexão metalingúística.

Questões como estas, aparentemente de caráter apenas pedagógico, requerem, todavia, uma análise mais ampla do ensino-aprendizagem da língua materna em sociedades capitalistas dependentes, caracterizadas pela existência de diferenças sócio-econômicas profundas entre as diversas classes sociais. Tal análise, por conseguinte, deveria partir de uma reflexão acerca do significado da LM à luz do signo linguístico enquanto efeito de estruturas sociais, das relações de poder que se configuram a partir dessas estruturas, da dominação ideológica e da identidade social, modelada ou não por esta ideologia dominante, elementos importantes para a compreensão das concepções e ações dos indivíduos.

No entanto, o tratamento teórico da questão do significado da LM tem sido marcado por reflexões que se contrapõem profundamente. De um lado, autores como Saussure (1982), que vêem a língua como um objeto abstrato ideal, sincrônico, homogêneo, rejeitando suas manifestações individuais (a fala). De outro, autores como o filósofo e linguista russo Mikhail Bakhtin (1988), que valoriza justamente a fala, a enunciação, afirmando sua natureza social, não-individual, ligada às estruturas sociais. É através da palavra que valores sociais distintos e contraditórios são confrontados. E este conflito torna-se mais evidente à medida que às diferenças de classe correspondem diferenças de variedades de fala. Para ele, toda variação linguística seria inerente à língua. Mesmo reconhecendo que ela, por um lado, obedece a certas leis internas é, sobretudo, regida por leis de natureza social.

Um exemplo disso são os critérios de correção linguística utilizados para classificar diferentes variedades sociais de fala como corretas e incorretas. Através da imposição de uma variedade de prestígio, vinculada à dominação de classe, esta variedade é de tal forma introjetada na consciência dos indivíduos, que estes passam a considerá-la como a única adequada, como modelo a ser copiado. Todavia, nem sempre os membros de uma comunidade linguística percebem as relações de força que se 
encontram por trás da formulação das normas linguísticas. Esta percepção depende do grau de consciência dos indivíduos, que, por sua vez, se relaciona com o desenvolvimento do seu processo de identidade, articulado diretamente à questão da ideologia.

Dentro de uma perspectiva histórica, a filosofia idealista, bem como a visão psicologista da cultura, situam a ideologia na consciência, determinando-a. Pressupõe-se, aqui, a existência de um vínculo mais abstrato entre as formas e as categorias mais gerais da criação ideológica. Já os seguidores do positivismo psicologista reduzem-na a um simples conglomerado de reações psicofisiológicas fortuitas que resultariam numa criação ideológica dotada de significação e unidade. Bakhtin (1988) critica ambas as correntes, reafirmando a natureza sócio-ideológica da consciência individual. A consciência só se torna consciência quando impregnada de conteúdo ideológico (semiótico) e somente no processo de interação social. A consciência forma-se a partir de signos criados por um grupo organizado no curso de suas relações sociais, sendo um reflexo de sua lógica e de suas leis.

Nesta perspectiva, a maioria dos estudiosos concorda que o processo de identificação é um fenômeno social e não individual, como se tentou fazer crer durante longo tempo, principalmente entre os filósofos idealistas e os psicologistas da cultura. Apesar deste consenso, duas posições distintas têm se confrontado. A primeira, de cunho funcionalista, concebe a identidade como o reconhecimento que o indivíduo tem de si, formado a partir de papéis normatizados socialmente, ou seja, padrões definidos a partir das necessidades da sociedade.

A outra concepção, de cunho histórico-marxista, considera também que a identidade é o reconhecimento de si, porém dado através do "reconhecimento recíproco dos indivíduos, identificados através de um grupo social que existe objetivamente, com sua história, suas tradições, suas normas, seus interesses" (Ciampa, 1984, p.64), sua ideologia.

Portanto, as formas e o conteúdo das relações estabelecidas entre classes sociais, num momento histórico determinado, constituem-se num aspecto 
fundamental para a formação da identidade, considerada aqui como um processo permanente, diretamente vinculada ao processo de comunicação ideológica que passa a se estabelecer especialmente através da linguagem, da palavra. Na medida em que um grupo social dominante coloca a sua marca mediante os conteúdos ideológicos de uma época, define assim aqueles valores que devem ser prestigiados e os que devem ser desprestigiados, utilizando, para isso, uma série de mecanismos, principalmente de comunicação verbal, para generalizar uma visão de mundo específica como se fosse universal e independente de qualquer classe, visando assegurá-la através do consenso. No caso da linguagem, na medida em que a classe dominante generaliza a sua variedade de fala como se fosse a variedade correta, única forma de expressão adequada, relegando as variedades de fala das classes subalternas a uma posição de segunda categoria, relegam também as visões de mundo dessas classes.

Esse processo, no entanto, não se dá de forma fechada nem ocorre sempre como espera a classe dominante. Discussão nesse sentido foi elaborada por Gramsci, especialmente no que se refere ao exercício da hegemonia ideológica das classes dominantes e das alternativas de superação da dominação ideológica, abrindo um importante foco de análise do conflito e enfrentamento ideológicos. A idéia da existência de ideologias diversas vinculadas a classes sociais antagónicas e a condições materiais de existência específicas, que aparece com destaque em Bakhtin (1988) e Gramsci (1978), não significa que essas ideologias façam parte de sistemas distintos e separados, mas sim de um mesmo sistema social, convivendo em interrelação e conflitos permanentes, apesar da dominação de um subsistema ideológico sobre o outro. Isto revela a estrutura dinâmica e complexa das lutas de classes e das dificuldades para a superação da dominação que, muitas vezes, é defendida pelos próprios dominados. $\mathrm{O}$ processo de identificação, que se dá em meio às lutas e aos confrontos que estão na base da dominação ideológica, e as consequentes representações e concepções dos indivíduos nem sempre se apresentam de forma clara, precisando, portanto, serem desvelados a partir das relações de classe das sociedades capitalistas em seus diversos aspectos. 
Dentro deste quadro teórico geral, faz-se necessário, ainda, estabelecer a correlação entre língua materna, identidade sócio-cultural e fracasso escolar na aprendizagem.

Segundo Porzig (1970), a língua materna faz parte das primeiras experiências de vida de um indivíduo e está estreitamente relacionada às características sócio-culturais de sua comunidade de fala. Em sua concepção, a língua que primeiro aprendemos desempenha um papel importante não só na construção da personalidade como é através dela que o indivíduo se identifica com outros de sua comunidade.

No entanto, a posição tradicional da escola, frente à aprendizagem da língua materna, é que os alunos das classes populares e falantes de variedade não-padrão substituam sua variedade linguística pela única variedade aceita como "correta" — a variedade-padrão das classes dominantes. Este processo leva o aluno a negar não apenas sua variedade de fala, mas também sua visão de mundo, descaracterizando sua identidade sócio-cultural.

Neste sentido, estudos de Labov (1972) evidenciam que a incompatibilidade entre os sistemas de valores da escola e dos alunos podem gerar desinteresse pela aprendizagem em sala de aula, quando a língua-padrão adotada pela escola se contrapõe às características sóciolingúístico-culturais da comunidade escolar.

A imposição da variedade-padrão, todavia, não se dá ao acaso, mas tem por base relações de poder e dominação, onde uma classe determinada, por assumir a direção económica e definir o projeto sócio-político para toda a sociedade, num momento histórico determinado, define também a direção ideológica, passando seus valores como universais e únicos de valor, trabalhando no sentido de convencimento de todos os outros segmentos a ela submetidos.

Um exemplo disso são os textos escolares trabalhados nas escolas, os quais se apresentam exclusivamente na variedade-padrão e cujos conteúdos são representativos das classes sociais médias e altas. A variedade linguística das classes populares é considerada, por conseguinte, como de 
segunda categoria. Isto não significa, todavia, que o ensino da variedadepadrão não seja desejável. Não devemos negar às classes populares o direito de conhecer um dos instrumentos de sua condição de dominados.

É inaceitável, portanto, que a escola considere o indivíduo, do ponto de vista linguístico, como uma tabula rasa, ignorando que eleja possui um conhecimento de língua, a sua variedade linguística, e que esta será sempre a sua matriz, o seu ponto de referência para a aquisição de outras variedades. A desconsideração desse conhecimento prévio pode trazer sérias consequências para o processo de alfabetização, dificultando a aprendizagem das crianças de classes populares e constituindo-se um dos elementos provocadores do seu fracasso.

A respeito do fracasso escolar, na aprendizagem da língua materna, duas teorias polémicas têm se confrontado: a Teoria do Déficit Linguístico e a Teoria das Diferenças Linguísticas.

A primeira baseia sua argumentação nos trabalhos publicados por Bernstein (1971) na década de 60 e na sua Teoria dos Códigos. Segundo ele, a criança, de acordo com sua classe social, seria classificada como falante de um código restrito ou elaborado, propondo uma relação causal entre classe social, linguagem e rendimento escolar. As implicações mais sérias de sua teoria consistem no fato de atribuir o déficit, que impede o sucesso social dos falantes "restritos", às diferenças entre os dois códigos linguísticos, e não às diferenças sócio-econômicas.

Em contrapartida, Labov (1972), um dos principais defensores da Teoria das Diferenças Linguísticas, procurou desmistificar os argumentos postulados pela Teoria do Déficit e a lógica que atribuía à privação linguística as dificuldades de aprendizagem das minorias étnicas socialmente desfavorecidas, dificuldades estas criadas pela própria escola e não originadas pela variedade não-padrão falada por essas minorias. Os argumentos de Labov baseiam-se nos resultados de seus próprios estudos e na crítica à maneira como foram obtidos os resultados nos quais se baseiam os partidários da Teoria do Déficit, afirmando que os experimentos são artificiais e assimétricos, e que adotam uma metodologia talvez 
adequada a pesquisas psicológicas, mas inteiramente inadequada à pesquisa sociolinguística. Para ele, "o mito do déficit verbal é particularmente perigoso porque desvia a atenção dos defeitos reais de nosso sistema educacional para defeitos imaginários da criança" (Labov, 1972, p.202). Tal mito conduziria a um determinismo sócio-cultural que acabaria por considerar os indivíduos de uma classe baixa como inerentemente inferiores e à hipótese falaciosa de que a uma manifestação linguística deficiente corresponderia uma capacidade cognitiva deficiente.

Estas considerações críticas oferecem-nos elementos para reflexões importantes sobre a prática de ensino da língua materna na escola, particularmente na escola pública. Como salientam Sampaio, Spinillo e Chaves (1987), "a apropriação da variedade social de prestígio de nossa língua pelas classes populares, bem como das formas de seu uso na sociedade, legitimadas pela classe dominante, pode, por si só, não garantir a erradicação das desigualdades sociais, mas certamente será um fator a menos dentre aqueles que contribuem para aprofundá-las".

\section{O experimento}

HIPÓTESES

Hipótese 1 - Sendo sua rede de interação pessoal mais heterogênea e, consequentemente, de textura mais frouxa, o processo de difusão (mistura) se intensificaria e o professor aproximar-se-ia da cultura dominante;

Hipótese 2 - Ao contrário, verifícando-se uma imobilidade social, o professor estacionaria socialmente como uma estratégia de "sobrevivência", integrando-se em redes de densa textura nos bairros periféricos, nas favelas ou invasões, criando-se condições para uma "focalização" da conservação da cultura popular. 


\section{Definição operacional das variáveis}

VARIÁVEIS SOCIAIS

a - Renda familiar

$\mathrm{b}$ - Idade

$\mathrm{c}$ - Origem

d - Identidade grupai (a identidade grupai foi expressa pelas variações linguísticas usadas pelos professores como um "ato de identidade")

e - Formação profissional (escolaridade)

VARIÁVEIS C O N C E I T U A I S / A Ç Õ E S

a - Concepção de ensino-aprendizagem de LM do professor

$\mathrm{b}$ - Ações

ESTUDO DE REDES

Descrição do processo de mobilidade sócio-econômica e de acesso aos bens culturais dominantes dos professores, associado ao desenvolvimento de tipos diferentes de redes de interação.

OS INSTRUMENTOS

Os instrumentos consistiram de: 1) uma entrevista individual contendo perguntas objetivas e subjetivas, com a finalidade de levantar as variáveis conceituais e sociais bem como indicadores dos tipos de vínculos da rede de interação pessoal dos professores, dentro e fora da comunidade onde trabalhavam; 2) observações naturais, em sala de aula, da ação pedagógica dos professores, seguindo-se o mesmo roteiro das questões teóricas da entrevista individual, com a finalidade de observar se havia 
uma correlação entre conceitos e ação pedagógica. Além disso, foi elaborado um roteiro de pontos relativos à forma como era trabalhada a linguagem oral e a língua escrita.

\section{Método}

A AMOSTRA

A amostra constituiu-se de 75 indivíduos selecionados aleatoriamente de um universo de 406 professores da $1^{\mathrm{a}}$ série do $1^{\mathrm{o}}$ grau de 96 escolas estaduais, distribuídas em 13 áreas do município do Recife, tomando-se como base a divisão político-administrativa, segundo o IBGE.

A METODOLOGIA

A metodologia de pesquisa adotada foi a de pesquisa qualitativa, em que o ambiente natural constituiu-se a fonte direta dos dados, caracterizados como predominantemente descritivos. Os procedimentos metodológicos implicaram um contato permanente do investigador com o ambiente e a situação investigada. Daí, a razão de a entrevista e de as observações naturais constituirem-se instrumentos-chave da pesquisa, enquanto elementos facilitadores para a apreensão da realidade dos sujeitos pesquisados.

\section{Resultados}

As considerações acerca do ensino da língua materna em um nível de compreensão teórica mais ampla constituíram-se pano de fundo para a análise de um segundo momento, em nível empírico, em que tomamos como referência sua articulação com a realidade concreta. 
Para realizarmos uma reflexão mais aprofundada sobre a relação entre as concepções dos professores alfabetizadores acerca de língua materna e prática pedagógica, tomamos como referência três categorias analíticas. ideologia, consciência e identidade sócio-cultural, articuladas à referência de classe dos sujeitos pesquisados.

Foram encontradas cinco categorias conceituais, formuladas a partir de uma análise qualitativa dos tipos de respostas e justificativas em relação às concepções de língua materna e à consciência das relações de poder que estão na base da legitimação de uma variedade de prestígio, e como estas questões, correlacionadas com diversas variáveis sociais, se refletem no ensino aprendizagem da língua portuguesa.

\section{Categorias conceituais}

\section{CATEGORIAS I E II}

As categorias I e II têm fortemente introjetadas os pressupostos teóricos da teoria do déficit linguístico em relação à variedade linguística falada pelas classes populares. A diferença entre ambas está no fato de a primeira relacionar o déficit linguístico a um déficit cognitivo e a segunda, à procedência do indivíduo à sua escolaridade.

O déficit linguístico também é reforçado pelas concepções dos professores em relação à definição de "correção" e "erro", concentrando suas justificativas em critérios gramaticais: "fala bem quem fala de acordo com a gramática normativa".

O professor, de um lado, não identifica a existência de diferenças entre variedades linguísticas e, de outro, não possui consciência do significado de "língua materna", o que pode ser verificado pelo seu desconhecimento da origem da diversidade de variedades linguísticas sociais. Por exemplo: Quando questionados porque determinadas pessoas falam diferente de outras, forneciam respostas do tipo: 
- ...tem ambiente que tem a falta de instrução...

- ...problema de dicção, o dom, eloquência, a cultura, o sotaque da pessoa, os vícios de linguagem, isto pode influir...

Outro traço marcante dessas duas categorias é a introjeção da cultura da classe dominante. Isto pode ser verificado nos conceitos manifestados pelos professores em relação à legitimação da variedade linguística da classe dominante. Por exemplo: Quando perguntados se concordavam que a variedade de fala na escola pública deveria ser a variedade falada pelas classes média e alta, forneciam os seguintes tipos de respostas:

- Concordo porque é a mais perfeita. O padrão deve ser usado por todos. - Concordo. A pessoa tem mais acesso à sociedade tendo contato com este padrão.

Essas categorias se caracterizam ainda pela total ausência de traços de identificação para com as classes populares, o que é sugerido em algumas respostas dos professores em relação ao item acima descrito ,pelo aceite tácito da hegemonia cultural imposta pela classe dominante, que passa a ser universalizada como se fosse independente das relações de força que estão na base de sua definição:

- O que determinou a escolha da variedade de fala das classes M/A foram os livros, os escritores que fazem a gramática.

- As leis que regem a língua portuguesa.

CATEGORIAS III E IV

As Categorias III e IV não assumem os pressupostos teóricos da teoria do déficit linguístico, muito embora os professores manifestem ainda um certo preconceito em relação à variedade popular, o que é sugerido pela associação da variedade-padrão aos padrões culturais e à escolaridade e da variedade não-padrão à linguagem do "povão". 
Todavia, observam-se algumas diferenças qualitativas em relação a ambas as categorias. Com relação à Categoria IV, os professores demonstraram perceber que variações linguísticas na linguagem oral, mesmo que pequenas, ocorrem tanto na variedade-padrão como na variedade não-padrão, propondo uma alternância no uso destas duas variedades:

- ...porque em tudo o que elas disseram não teve erro de concordância; o erro que houve foi uma besteira e eu o vi nas duas. O que importa é que o objetivo das duas foi atingido. Não há o que recriminar.

- Se ela for falar para um público (referindo-se ao falante de VP), ela é incorreta, porque se tiver pessoas do povo estas não vão entender o que ela disse; ela teria que usar uma linguagem mais popular.

- Se ela estiver falando para pessoas do povo (referindo-se ao falante de VP), está correta; se estiver falando para outro público, está incorreta. Falar correto significa falar de acordo com o público que a assiste.

Todavia, ambas as categorias não possuem consciência clara do significado de língua materna, o que pode ser verificado pelo seu desconhecimento da origem da diversidade de variedades linguísticas sociais:

- A primeira é aquela pessoa que gosta de querer aparecer. A segunda é uma pessoa simples, que você entende tudo o que ela falou. Uma pessoa simples que soube exprimir seu pensamento.

— Problema de localidade...

— Nível sócio-econômico...

Ambas as categorias têm introjetadas a cultura da classe dominante, sendo que na categoria IV esta introjeção é mesclada por um sentimento de identificação com a cultura popular - o que não ocorre na Categoria III. Isto pode ser verificado nos conceitos manifestados pelos professores em relação à legitimação da variedade linguística da classe dominante. Por exemplo: Quando perguntados se concordavam que a variedade de fala da escola pública deveria ser a variedade falada pelas classes média e alta, os professores forneciam o seguinte tipo de resposta: 
- Sim. Mas apenas devido ao contexto que a gente vive, porque se eu pudesse mudar isso, mudaria; cada um falaria e escreveria como quisesse.

Em relação à Categoria III, observa-se a ausência de uma consciência da dominação cultural e económica exercida pelas classes média e alta para a legitimação de uma variedade de prestígio, à medida que manifestam a crença de que a legitimação de uma variedade de fala se dá porque existe uma variedade e uma classe social superior:

- ...o nível cultural da classe média que tem o Português correto por causa do estudo.

A esse respeito, na Categoria IV, os professores percebem esta dominação cultural:

- O sistema social é que determinou a escolha, talvez só para eles entenderem.

CATEGORIA V

Os indivíduos da Categoria V não assumem os pressupostos teóricos da teoria do déficit linguístico, uma vez que consideram tanto uma variedade como a outra corretas:

- Ambas são corretas, à medida que expressam o sentimento de cada um. Agora, a maneira de expressão foi diferenciada. Cada uma dentro de suas limitações gramaticais. Uma fala sem o aparato académico; a segunda, o saber popular, a linguagem do cotidiano. O senso comum é um saber fragmentado, desarticulado. A outra é o inverso, passou para a consciência filosófica, um saber mais articulado.

- Porque o que a gente fala é certo em termos gramaticais, mas aí vem toda a cultura de um povo que representa a maioria. Será que todos falam errado e só a gente fala certo? 
Muito embora ambas as variedades linguísticas tenham sido consideradas correias, o professor não possui consciência clara do significado de língua materna, o que pode ser verificado pelo seu desconhecimento da origem da diversidade de variedades linguísticas sociais:

- Porque cada pessoa tem suas características próprias.

— Depende do nível sócio-econômico-cultural das pessoas.

Esta foi a única categoria onde os professores demonstraram ter uma consciência nítida da relação de força entre classes sociais, que está na base da legitimação de uma variedade de prestígio. Isso pode ser verificado em relação ao que teria determinado a escolha da variedade linguística das classes média e alta como a variedade oficial a ser ensinada na escola pública:

— O poder económico determina o modo "correto" de fala, e o fato desta se aproximar mais do português culto, "correto", fez com que essa fala fosse determinada oficial.

Esta categoria caracteriza-se também pela identificação com as classes populares. Isto pode ser verificado nos conceitos manifestados pelos professores sobre se a variedade da fala, ensinada na escola pública, deveria ser a das classes média e alta:

— Não concordo. A linguagem das camadas populares deveria ser melhor aproveitada e não relegada. Esta fala também tem o seu valor social.

A tabela abaixo apresenta a frequência dos professores em cada uma das categorias: 


\section{Tabela 1 - Freqüência dos sujeitos por categorias conceituais}

\begin{tabular}{l|c|c}
\hline Categorias & $\mathrm{N}^{\circ}$ & $\%$ \\
\hline I-II & 36 & 48, \\
III & 25 & 33,3 \\
IV & 10 & 13,3 \\
V & 04 & 5,4 \\
\hline & 75 & 100 \\
\hline
\end{tabular}

As categorias conceituais apresentam uma frequência progressiva com relação a uma ausência ou presença de traços indicativos de uma maior ou menor aproximação conceituai linguística e cultural, da parte dos professores para com as classes dominantes ou com as classes dominadas. Observa-se também que as diferenças entre estas frequências progressivas são bastante significativas.

A categoria qualitativamente mais próxima das Categorias I e II, em termos de traços indicativos de uma maior identificação para com os valores linguístico-culturais das classes dominantes (muito embora não assuma a Teoria do Déficit), é a Categoria III. Em relação à Categoria IV, embora apresente, de um lado, traços indicativos de uma identificação lingúístico-cultural, embora pouco consciente, para com as classes populares, representa, todavia, apenas $13,3 \%$ da amostra total. As frequências em direção a uma maior identificação para com as classes populares são ainda mais afuniladas em relação à Categoria $\mathrm{V}$, que representa apenas 5,3\% da amostra total.

Os resultados sugerem também que existe uma correlação entre as concepções dos indivíduos das Categorias I, II, III, IV e V, suas idades, renda e escolaridade, conforme demonstrado no quadro abaixo: 


\section{Quadro 1 - Resultados obtidos na correlação entre variáveis sociais}

e as categorias conceituais

\begin{tabular}{|c|c|c|c|c|c|c|c|c|c|c|}
\hline $\begin{array}{l}\text { Variáveis/ } \\
\text { Categorias }\end{array}$ & Sign. & $\begin{array}{l}\text { Prob. Sign } \\
\text { (Variância) }\end{array}$ & $\mathrm{H}_{e}$ & $\mathrm{H}_{\mathrm{c} \text { a }}$ & $x^{2}$, & $x^{2}$ & $Z_{s}$ & $\mathrm{Z}_{\mathrm{ub}}$ & $\mathrm{U}_{\mathrm{s}}$ & $U_{t a b}$ \\
\hline \multirow{4}{*}{$\begin{array}{l}\text { 1.Idade } \\
\text { I-II,III,IV e V } \\
\text { l-II,III e IV } \\
\text { IV e V }\end{array}$} & & & & & & & & & & \\
\hline & - & $0,05-0,10^{*}$ & 6,9 & 6,25 & - & - & - & - & - & - \\
\hline & - & $080-0-0,90$ & 0,37 & 4,6 & - & - & - & - & - & - \\
\hline & - & - & - & - & - & - & - & - & $5^{*}$ & 7 \\
\hline \multicolumn{11}{|l|}{ 2. Origem } \\
\hline IV e V & $0,10-0,20$ & - & - & - & 2,5 & 2,71 & - & - & - & - \\
\hline \multicolumn{9}{|l|}{ 3. Renda } & & \\
\hline IV e V & - & - & - & - & - & - & - & - & $9^{*}$ & 0 \\
\hline I-II,III e IV & - & 0,10 & - & - & - & - & - & - & - & - \\
\hline \multicolumn{11}{|l|}{ 4.Escolaridade } \\
\hline I-II,III e IV & 0,02 & - & - & - & 0,02 & 4,6 & - & - & - & - \\
\hline IV e V & $0,0681^{*}$ & - & - & $\cdot$ & - & $\cdot$ & 1,49 & 1,28 & - & - \\
\hline \multicolumn{11}{|l|}{ 5.Identidade } \\
\hline I-II e III & 0,1635 & - & - & - & 0,98 & 1,28 & - & - & - & - \\
\hline III e IV & 0,2912 & - & - & - & 0,55 & 1,28 & - & - & - & - \\
\hline I-II e IV & 0,422 & - & - & - & 0,12 & 1,28 & - & - & - & - \\
\hline
\end{tabular}

Aponta correlação entre as variáveis sociais e as categorias conceituais

Curiosamente, os indivíduos da Categoria V, que apresentaram conceitos mais compatíveis com uma identificação para com as classes populares, são os que apresentaram a média mais baixa de idade $(24,7 \%)$, a média mais alta de renda $(13,5 \%)$ e a frequência mais alta de escolaridade (100\% com curso superior), em relação à média e à frequência mais altas das três outras categorias: I e II — 37,2\% (idade), 11,06\%» (renda), 13,92\% (curso superior); III - 35,7\% (idade), 9,18\% (renda), 9,67\% (curso superior); IV — 34,3\%» (idade), 7,7\% (renda) e 3,87\% (curso superior).

Estes resultados são sugestivos de que os professores mais jovens, de maior renda e nível de escolaridade são aqueles que, conceitualmente, 
possuem um perfil cujos traços se aproximam dos valores linguísticos e culturais das classes populares.

Com relação à variável "identidade" (caracterizada pela conservação ou não de variações linguísticas não-padrão na linguagem oral dos professores), muito embora as baixas frequências por categoria (Categorias I e II - 10; Categoria III - 10 e Categoria IV - 3) não tenham permitido a verificação de diferenças entre categorias, aquela variável chama a atenção com relação a uma particularidade.

Em termos de uma análise qualitativa, verifica-se que os professores da Categoria IV, que se diferencia das Categorias I e II e da Categoria III por apresentar contradições conceituais em relação ao eixo introjeção da cultura dominante/identificação linguístico-cultural para com as classes populares, além de possuírem a renda mais baixa da amostra, não refletem essas diferenças no nível da variável identidade. O fato de os indivíduos de renda mais baixa não conservarem mais, no nível da comunicação social ou extrafamiliar, uma variedade de fala não-padrão pode ser sugestivo de que ou não conservam mais essas variações — o que implicaria numa perda de identidade e aculturação - ou desenvolveram a habilidade de utilizar uma e outra variedade linguística de acordo com a situação de comunicação (formal ou informal, social ou familiar) ou de acordo com essa situação e devido à situação do interlocutor-falante de classes sociais distintas.

\section{Categoria de ação e tipos de práticas pedagógicas}

Foi observada apenas uma única categoria de ação onde foram enquadrados todos os professores da amostra. Essa categoria foi caracterizada com base na observação da postura dos professores em sala de aula, com relação às variedades linguísticas das crianças e à prática de ensino da variedade-padrão.

Constatou-se que o professor não leva em consideração a experiência 
linguística anterior das crianças, tanto no nível oral como na escrita, estigmatizando as variedades linguísticas dos alunos, ao impor a variedadepadrão como a única variedade boa, correta e aceitável, não demonstrando consciência clara de que essas variações implicam dificuldades para a aprendizagem da variedade popular.

A estigmatização evidencia-se pelo fato de os professores raramente se referirem à variedade linguística da criança como uma variedade de fala, mas sim aos seus "vícios de linguagem". E quando esses "vícios" surgem em sala de aula, ou eles são simplesmente ignorados, uma vez que não recebem um tratamento em nível de linguagem, ou são simplesmente corrigidos sistematicamente, "sem que as crianças o percebam", ou seja, o professor repete oralmente a forma "correta" ou a escreve no quadro, sem jamais fazer alusão à forma utilizada pela criança.

Exemplos: Os professores, quando questionados sobre a maneira como trabalham as diferenças entre fala e escrita e língua falada e língua escrita, forneciam justificativas como:

— Quando ele (o aluno) fala a "palavra de casa", eu ensino a palavra certa. Eu digo a ele que a linguagem de casa não é tão correta. Às vezes, os próprios colegas corrigem, ridicularizando-o. Aqui varia muito em função da área (a fala varia). Quem vê família, vê criança. No nível da escrita, eu corrijo a palavrinha. Quando eles erram muitas vezes, o castigo é escrever a palavrinha certa várias vezes.

Com relação ao trabalho do professor com as diferenças entre fala e escrita:

— Por exemplo: "asa". O som é de "z", mas se escreve "s". Eu sou muito gramatical, muito normativa. Eu digo que não é assim, que está errado.

O desconhecimento, por parte dos professores, de que as variações linguísticas de variedades não-padrão implicam dificuldades para a aprendizagem da variedade-padrão, evidencia-se pelos depoimentos que se seguem. 
Quando questionados sobre as dificuldades observadas em relação à aprendizagem da leitura e da escrita dos alunos, os professores forneciam justificativas do tipo:

- Crianças que vieram do lar não têm acompanhamento em casa. Deficiência visual, miopia aguda...

Raros foram os professores que apontaram como dificuldades:

- As "não-equivalências entre grafia e som".

- Eles falam de acordo com a linguagem do meio deles.

Apesar de apontar as variedades de fala dos alunos como dificuldade, os professores desconhecem os níveis dessas dificuldades (fonológico, morfossintático e lexical).

Dentro da categoria de ação descrita, foram ainda observados oito tipos de práticas pedagógicas que não apresentam uma progressão qualitativa, mas apenas características que as diferenciam entre: uma prática com características opostas a pressupostos teóricos específicos sobre como trabalhar a competência linguística dos alunos (Prática I); práticas com características contraditórias (Práticas III, IV e V) e práticas com características mais próximas a esses pressupostos teóricos (Práticas VI, VII e VIII).

Não obstante, considerando-se os resultados como um todo, as diferenças verificadas em relação aos tipos de práticas não alteram a ação do professor quanto ao tratamento dispensado às variedades linguísticas dos alunos no ensino da variedade-padrão: a de desconsideração, ou de desconsideração e estigmatização. 


\section{Rede de relações: densidade e multiplicidade}

O perfil do professor quanto a sua rede de relações foi construído a partir de dois níveis:

Densidade: - No qual se procura verificar a inserção dos professores na comunidade em que trabalham.

Multiplicidade: - No qual se procura avaliar a posição dos professores quanto a certos valores definidos a partir de uma perspectiva de classe determinada, especificamente das classes dominantes.

Foram estabelecidos escores de rede funcionando como índices do grau de proximidade (afiliação, identidade) do professor com a comunidade da escola onde trabalha e com grupos de referência fora da comunidade. Os escores referem-se a noções-chave da rede pessoal (de relativa densidade e multiplicidade), utilizando diversos atributos dessas duas redes.

$\mathrm{Na}$ análise quantitativa, as médias de frequência dos escores de densidade e multiplicidade foram inicialmente distribuídas, separadamente, por categorias conceituais, para a verificação do grau de inserção do indivíduo na comunidade (densidade) e do grau de aproximação para com os valores da cultura dominante (multiplicidade). Foi feita também uma correlação ordinal entre as médias dos escores de densidade e multiplicidade por categorias conceituais para verificar se a uma alta densidade corresponderia uma baixa multiplicidade e vice-versa. Além disso, foi verificada ainda a correlação entre as categorias conceituais e as médias dos escores da rede de relações. A tabela abaixo apresenta as médias dos escores da rede de relações (densidade e multiplicidade) por categoria. ${ }^{1}$

IPara fins de teste estatístico considerou-se apenas quatro categorias conceituais, tendo em vista que as Categorias I e II são idênticas quanto ao pressuposto teórico (a Categoria I relaciona déficit linguístico a um déficit cognitivo e a Categoria II relaciona déficit linguístico à procedência do indivíduo). 


\section{Tabela 2 - Médias dos escores de rede de relações (densidade e multiplicidade) por categoria conceituai}

\begin{tabular}{l|c|c|c|c}
\hline Categorias & I-II & III & IV & V \\
\hline Densidade & 4,2 & 5,6 & 5,5 & 2,0 \\
Multiplicidade & 7,5 & 6,8 & 6,5 & 4,2 \\
\hline
\end{tabular}

A Tabela 2 evidencia elementos importantes, quando fazemos uma análise comparativa entre categorias.

Considerando as categorias I e II, que se definem, quanto aos padrões conceituais, pela maior aproximação com os valores linguístico-culturais da classe dominante, podemos verificar que, em termos de densidade, apesar de não serem a maior média da amostra, apresentam-se bem mais próximas das médias mais altas (Categorias III e IV) e distantes da média mais baixa (Categoria V).

Em relação à multiplicidade, apresentam a média mais alta de toda a amostra, o que significa uma maior aproximação com os valores linguístico-culturais das classes dominantes, corroborando, inclusive, os resultados obtidos quanto ao nível conceituai. Isso demonstra que os indivíduos dessa categoria, apesar de apresentarem um relativo grau de inserção na comunidade em que trabalham, apresentam maior aproximação com os valores das classes dominantes.

Em termos de médias de densidade e multiplicidade, as Categorias III e IV apresentam-se estatisticamente próximas às Categorias I e II (Categoria III = 5,6 e 6,8; Categoria IV = 5,5 e 6,5).

No entanto, apesar dessa proximidade revelada nos dados absolutos das médias de densidade e multiplicidade descritos acima, uma análise qualitativa desses dados, comparados aos dados apresentados quanto ao nível conceituai, revela resultados distintos. Verifícou-se, por exemplo, que a aproximação com valores linguístico-culturais da classe dominante, 
no que se refere à Categoria IV, dá-se em meio a contradições significativas, contradições que se evidenciam através de diversas respostas em que ora se reconhecem os valores linguísticos e culturais das classes dominantes, ora se desvaloriza a variedade de fala dessa classe, valorizando-se a variedade da classe popular.

A Categoria $\mathrm{V}$, que se define em termos conceituais pela consciência da relação de força entre classes sociais que está na base da legitimação de uma variedade de prestígio, identificando-se com a classe popular, apresenta a mais baixa densidade e multiplicidade em termos de média da amostra (2,0 e 4,2, respectivamente). Esses dados são sugestivos de que a um baixo nível de inserção dos professores na comunidade corresponderia uma relativa aproximação com os valores das classes populares.

O nível de significância entre as diferentes médias de densidade e multiplicidade por categoria foi verificado através dos testes "U" de Mann - Whitney e "U", que apontaram resultados que confirmam as comparações entre as médias dos escores das categorias feitas com os dados absolutos.

\section{Quadro 2-Resultados obtidos na correlação entre categorias conceituais} e médias dos escores da rede de relações (densidade/multiplicidade)

\begin{tabular}{|c|c|c|c|c|c|}
\hline $\begin{array}{l}\text { Densidade/Multiplicidade/ } \\
\text { Categorias Conceituais }\end{array}$ & Signif. & $Z_{c}$ & $\mathrm{Z}_{\mathrm{tab}}$ & $\mathrm{U}_{\mathrm{c}}$ & $\mathrm{U}_{\mathrm{tab}}$ \\
\hline $\begin{array}{l}\text { Densidade } \\
\text { I-II e IV } \\
\text { I-II e V } \\
\text { IV e V }\end{array}$ & $\begin{array}{l}0,1841 \\
0,0721^{*} \\
5 \%\end{array}$ & $\begin{array}{l}0,9 \\
1,46\end{array}$ & $\begin{array}{l}1,28 \\
1,28\end{array}$ & 6,5 & 7 \\
\hline $\begin{array}{l}\text { Multiplicidade } \\
\text { I-II e IV } \\
\text { I-II e V } \\
\text { IV e V }\end{array}$ & $\begin{array}{l}0,0001^{*} \\
0,0037 \\
5 \%\end{array}$ & $\begin{array}{l}3,2 \\
2,68\end{array}$ & $\begin{array}{l}1,28 \\
1,28\end{array}$ & 7 & 7,5 \\
\hline
\end{tabular}

* Aponta correlação entre as categorias conceituais e as médias dos escores da rede de relações. 
Observamos, ainda, que a Categoria $\mathrm{V}$ apresentou a maior média de renda da amostra $(13,5)$, maior nível de escolarização (100\% com curso superior), bem como a média de idade mais baixa da amostra $(23,7)$.

Esses dados são sugestivos de que, apesar dessa categoria apresentar o mais baixo nível de inserção na comunidade (densidade), em termos de média, de se constituir o estrato mais alto da amostra em termos de renda e nível de escolarização, além de ser a única categoria que não apresenta frequência quanto ao aspecto de identidade linguística com as classes populares, aproxima-se mais dessa classe (multiplicidade mais baixa da amostra - 4,2) ou, pelo menos, reconhece nesses valores uma forma diferente de percepção do mundo.

\section{Discussão e conclusões}

Esta pesquisa, que teve como objetivo fundamental traçar o perfil de uma amostra de professores da rede de ensino público da cidade do Recife, quanto às suas concepções de língua materna, tentando verificar até que ponto essas concepções influenciavam práticas pedagógicas determinadas, apresentou resultados bastante significativos. Esses resultados, de um lado, possibilitaram a compreensão da relação dialética do signo enquanto efeito das estruturas sociais, bem como em que medida a identidade social, modelada (ou parcialmente modelada) pela ideologia dominante, condicionou as concepções e a ação pedagógica dos professores. Além disso, a contraposição de ambas possibilitou a identificação da dificuldade de articulação entre teoria e prática e uma reflexão sobre as possibilidades de sua superação. De outro, permitiu o aprofundamento da discussão do próprio processo de identificação, na perspectiva de uma dinâmica social global que tem por base relações de classes determinadas historicamente, onde se delineiam e se afirmam as ideologias dominantes e as contraideologias. 
A primeira conclusão a que chegamos é a de que a maioria dos indivíduos da amostra (81,3\%, Categorias I-II e III) que representa o universo de professores-alfabetizadores da cidade do Recife, que atendem a uma clientela de classe popular e com características linguísticas e culturais específicas, apresenta um perfil cujos traços conceituais estão acentuadamente voltados aos valores lingúístico-culturais das classes dominantes, enquanto uma pequena parte da amostra apresenta um perfil cujos traços conceituais se aproximam dos valores lingúístico-culturais das classes populares.

No que se refere às Categorias I-II e III, a própria concepção de língua reflete uma falsa consciência do seu significado, à medida que é concebida como uma entidade neutra que está acima dos falantes, independentemente de classes sociais e, por conseguinte, irredutível a leis, sejam elas de caráter ideológico, artístico ou outras quaisquer.

Nesta concepção não há espaço para uma reflexão acerca do papel do falante na construção de sistemas linguísticos - o que poderia facilitar o reconhecimento da existência e do papel da língua materna para o desenvolvimento da consciência. Ao contrário, à medida que a variedade linguística não-padrão é identificada como um desvio ou uma deformação da gramática normativa, ela sequer assume o status de uma variedade linguística enquanto um sistema de formas fonéticas, morfossintáticas e lexicais que apresenta suas especificidades.

A ideologia dominante está de tal forma introjetada na consciência dos professores, a ponto de a variedade de prestígio e, com ela, outros significados (como o próprio conceito de cultura) passarem a ser universalizados como se fossem independentes das relações de força que estão na base de sua definição. Neste particular, associa-se à variedade não-padrão a falta de "cultura", "de escolaridade" (como nas Categorias II-III) ou a existência de um déficit cognitivo (como na Categoria I) que resultaria da própria associação entre variedades populares, déficit linguístico e déficit cultural.

Com relação às Categorias IV e V, muito embora também não exista uma compreensão clara sobre a natureza real da linguagem enquanto signo ideológico (que passa pela concepção de língua, de variedades linguísticas 
e de língua materna), estas distinguem-se das três primeiras por uma característica muito significativa: a identidade, manifestada em cada categoria por diferentes graus de consciência.

Enquanto nas demais categorias (I-II e III) a variedade não-padrão não é sequer reconhecida como uma variedade linguística, na Categoria IV ela adquire o status de uma variedade social cujas variações não se constituem um obstáculo para a concretização da comunicação. Nesta concepção há espaço para uma reflexão acerca da relatividade da norma linguística, à medida que se reconhece que falar correto significa falar de acordo com as convenções admitidas e prestigiadas por determinados segmentos sociais, pertençam eles às classes popular ou dominante. Todavia, o grau de consciência desta categoria resume-se aos estreitos limites da compreensão de que essa variedade atenderia à finalidade comunicacional. Muito embora a questão da legitimação de uma variedade de prestígio não seja colocada como inquestionável (a exemplo das Categorias I-II e III), ela também é aceita: de um lado, como uma manifestação de impotência diante de uma ordem social estabelecida e, de outro, como uma forma de superação das diferenças sociais - papel reservado à "escola"—, que possibilitaria às classes populares a apropriação da variedade de prestígio que as conduziria à ascensão social.

A esse respeito, na Categoria $\mathrm{V}$, questiona-se a legitimidade da variedade-padrão, à medida que há uma consciência de que se a linguagem é um bem cultural, qual a razão de uma variedade linguística, compartilhada pela maioria de um povo, não ter legitimidade social?

Com relação à consciência da dominação cultural e económica exercida por uma classe social determinada, a Categoria $\mathrm{V}$ é a única que reflete a relação de força entre classes sociais que está na base da legitimação de uma variedade de prestígio.

Como última reflexão acerca dessas duas categorias, é necessário ressaltar que, embora contraditórias em seus avanços e limites com relação às suas concepções quanto à natureza da linguagem, refletem a relação 
dialética entre dominação e resistência que se dá no confronto de classes sociais.

As considerações que realizamos a partir da discussão da forma como a natureza da linguagem é percebida nas diversas categorias conceituais remete-nos a uma análise de sua articulação com os processos de identificação, fundamentais para a compreensão da própria formação da consciência e do pensamento com base na atividade mental em língua materna.

Nesse sentido, o perfil dos indivíduos quanto às concepções acerca da língua materna foi ainda analisado, considerando-se a sua rede de relações sociais (densidade e multiplicidade) e algumas variáveis sociais.

Os resultados verificados, no que se referem às Categorias I-II e III, mostram que a uma relativa inserção na comunidade (noção de densidade de rede) correspondeu uma aproximação para com os valores da classe dominante (noção de multiplicidade de rede).

Quanto à Categoria V, esta correspondência se deu de forma inversa: a uma menor inserção dos indivíduos na comunidade (baixa densidade) correspondeu um distanciamento dos valores da classe dominante (baixa multiplicidade).

No que se refere à Categoria IV, esta apresenta uma singularidade que a distingue das demais: se, por um lado seus sujeitos também apresentam uma relativa inserção na comunidade à qual correspondeu uma aproximação para com os valores dominantes, por outro, ela contradiz essa aproximação à medida que, no nível conceituai, apresenta uma forte rejeição à variedade de prestígio.

Comparando esses resultados com as variáveis sociais, especialmente quanto ao nível de renda e escolaridade, observamos que a Categoria $V$ é a que mais se aproxima dos valores linguístico-culturais das classes populares, tanto em termos conceituais quanto de multiplicidade. Contrariamente ao que se poderia esperar, é a que apresenta a média de renda e escolaridade mais alta da amostra - aspecto sugestivo de que seus sujeitos não pertenceriam às classes populares. $\mathrm{O}$ fato de essa 
categoria ser a única que não registrou frequência de indivíduos que conservam, na linguagem oral, variações linguísticas não-padrão parece corroborar essa suposição.

Quanto às Categorias I-II e III, o processo dá-se de forma inversa. Estas categorias, que se caracterizam pela aproximação com os valores dominantes, apresentam baixos níveis de renda e escolaridade, comparadas à Categoria $\mathrm{V}$ - aspecto sugestivo de que seus sujeitos pertenceriam às classes populares.

Com relação à Categoria IV, esta se constitui um estrato inferior, em termos de renda (a mais baixa de toda a amostra) e escolaridade, ao da Categoria V (a mais alta da amostra) - aspecto sugestivo de que os professores pertenceriam às classes populares. Apresenta, ainda, uma inserção na comunidade bem mais significativa do que a Categoria $\mathrm{V}$ (densidade mais baixa da amostra). No entanto, esta categoria, como já afirmamos anteriormente, se caracteriza por contradições fundamentais que oscilam entre dois pólos: o da introjeção da cultura dominante (que se evidencia pela própria introjeção ao pressuposto de uma privação cultural existente nas classes populares) e a identificação para com os valores lingíístico-culturais das classes populares (evidenciada pela "defesa" da variedade linguística não-padrão e, em alguns casos, a rejeição da variedade-padrão).

Contraditoriamente, nesta categoria conceituai registrou-se uma baixa frequência de indivíduos que conservam variações linguísticas não-padrão, o que poderia sugerir uma perda de identidade ou aculturação ou o desenvolvimento de uma competência linguística de utilização de uma ou outra variedade de acordo com o contexto de comunicação. Mesmo que os dados não nos permitam confirmar ou negar qualquer uma das suposições, se considerarmos os mecanismos de reprodução cultural que estão por trás da instituição escolar, os conceitos, valores, ações e práticas com relação ao ensino-aprendizagem de nosso idioma pátrio, dificilmente este conjunto organizado de significados contribuiria para a formação de uma competência linguística de "duplamão", onde o falante selecionaria 
uma ou outra variação de fala por conta de uma compreensão crítica da relação de força que está na base da legitimação de uma variedade linguística de prestígio, sem implicar perda de identidade ou processo de aculturação.

A análise desses resultados não confirmou a hipótese inicial. Esperávamos que a uma alta densidade correspondesse uma baixa multiplicidade, isto é, a uma alta inserção do indivíduo na comunidade correspondesse uma menor aproximação para com os valores das classes dominantes, uma vez que tínhamos como hipótese que, "sendo a rede de interação pessoal mais heterogénea e, consequentemente, de textura mais frouxa, o processo de difusão (mistura) se intensificaria e o professor aproximar-se-ia da cultura dominante". Ao contrário, "verifícando-se uma imobilidade social, o professor estacionaria socialmente como uma estratégia de sobrevivência, integrando-se em redes de densa textura nos bairros periféricos, nas favelas ou invasões, criando-se condições para uma 'focalização' da conservação da cultura popular".

$\mathrm{O}$ aprofundamento em torno da discussão desses resultados, no entanto, nos conduziu a uma segunda conclusão fundamental: que a inserção do indivíduo na comunidade de classes populares e a sua vinculação a essas classes não apresentam uma relação determinante com uma aproximação/ afastamento para com valores lingúístico-culturais das classes dominantes. Esta conclusão, por sua vez, nos sugere elementos importantes para a análise de processos sociais determinados, especialmente o processo de identificação social, a partir da perspectiva que considera a hegemonia ideológica exercida por uma classe como aspecto fundamental.

Nessa perspectiva, poderíamos considerar que o processo de identidade social dos indivíduos se daria não apenas como resultado de uma relação direta com a comunidade em que o mesmo se insere, ou mesmo com a classe social a que pertença ${ }^{2}$. Este processo se dá, na realidade, em meio a visões de mundo

${ }^{\mathrm{z}}$ Discuss3o importante acerca da consciência (identidade) de classe foi elaborada por Marx, através dos conceitos de "classe em si" e "classe para si". 
diferenciadas e até antagónicas, vinculadas e produzidas a partir das condições materiais de existência de classes sociais específicas que se interrelacionam permanentemente. Essa relação, que se constitui predominantemente como uma relação de força, é marcada pela dominação de uma visão particular que é imposta a toda a sociedade como a mais adequada.

Nesse processo, o qual consideramos significativo para a análise das Categorias I-II e III, a classe popular é alienada de sua visão de mundo particular, geralmente negando-se como classe, legitimando valores culturais estranhos a sua própria visão, reconhecendo-se inclusive como inferior e de segunda categoria.

Considerando as Categorias IV e V, o nível de contradições quanto ao processo de aproximação/afastamento para com os valores dominantes pode ser sugestivo de que a dominação ideológica de uma classe determinada não se dá de forma plena, tanto no nível da formação da consciência individual quanto no nível das relações mais globais que caracterizam qualquer formação social com base na dominação de classe. Este processo constitui-se um elemento fundamental para a compreensão das possibilidades e dos limites da superação da dominação, uma vez que é nele que se articulam as formas de resistência à dominação.

A esse respeito, na análise sobre a hegemonia ideológica exercida pela classe dominante, vale destacar a contribuição de alguns autores, entre eles Gramsci, que discute justamente as possibilidades e os limites da conquista de uma hegemonia ideológica diversa da dominante, como fator fundamental para a transformação social.

Neste trabalho foram correlacionadas também as concepções sobre ensino-aprendizagem da LM e a prática do professor-alfabetizador. Observou-se que todas as categorias conceituais se inserem numa única categoria de ação pedagógica, caracterizada pela desconsideração e estigmatização das variedades linguísticas dos alunos e pela falta de uma consciência clara de que essas variações implicam dificuldade para a aprendizagem da variedade-padrão, tanto na forma oral como na forma escrita. 
Em relação à categoria de ação mencionada, observaram-se, ainda, oito tipos de práticas cujas diferenças, em termos qualitativos, não foram substanciais para o estabelecimento de uma correlação entre categoria conceituai, categoria de ação e tipos de prática.

No que se refere às categorias conceituais I-II e III, observamos uma correspondência entre suas concepções acerca da LM—onde é reconhecida e legitimada a variedade de prestígio das classes $\mathrm{M}$ e A e a categoria de ação - em que é estigmatizada a variedade das classes populares.

A Categoria IV, muito embora se diferencie das duas primeiras por apresentar contradições quanto à relação aproximação-afastamento dos valores culturais da classe dominante, questionando a legitimidade de sua variedade linguística, no nível de ação não se modifica, sendo idêntica às categorias conceituais I-II.

Com relação à Categoria $\mathrm{V}$ - que se destacou das demais em termos conceituais por se constituir a única categoria que reflete a relação de poder entre classes sociais que está na base de legitimação de uma variedade de prestígio —, no nível de categoria de ação também não se diferencia das demais.

Essa falta de articulação entre as concepções da LM do professoralfabetizador e sua ação pedagógica, particularmente no que se refere às categorias conceituais IV e V, que se diferenciam das demais por conceberem a variedade não-padrão como variedade legítima das classes populares, nos conduzem a uma terceira conclusão importante: que o simples reconhecimento, em nível conceituai, da legitimidade da variedade de fala das classes populares não conduz, necessariamente, a uma prática pedagógica que reconheça e legitime a variedade não-padrão, evidenciando, portanto, a dificuldade de articulação entre teoria e prática.

Essa conclusão se constitui um importante aspecto a ser considerado para a discussão das possibilidades de mudança na prática pedagógica do professor-alfabetizador, pois, mesmo quando existe uma consciência da relação de força que está na base da legitimação dos bens culturais da classe dominante, a articulação desse conhecimento com a ação prática não se efetiva, dando-se continuidade a um processo de reprodução cul- 
tural das classes dominantes sobre as dominadas, num círculo vicioso, evidenciando a força da dominação ideológica da classe dominante, que reproduz a sua dominação cotidianamante nas relações sociais concretas em todos os níveis da sociedade.

Os resultados deste estudo sugerem a necessidade de serem desenvolvidas outras investigações que aprofundem o problema do desenvolvimento da formação da consciência com base na atividade mental em língua materna, e que levem em consideração, especialmente, as variedades linguísticas sociais das classes populares.

Finalmente, embora reconhecendo sua especificidade, esperamos que este trabalho tenha contribuído para a compreensão da natureza da hegemonia cultural exercida pelas classes dominantes sobre as dominadas e de como o ensino de uma variedade de prestígio da língua portuguesa pode ser usado como instrumento de manipulação que assegura essa relação de dominação.

\section{Referências bibliográficas}

BAKHTIN, M. Marxismo e filosofia da linguagem: problemas fundamentais do método sociológico na ciência da linguagem. São Paulo: HUCITEC, 1988.

BERNSTEIN, B. Classe, codes andcontrol: theoretical studies towards a sociology of language. London: Routhledge \& Kegan Paul, 1971.

CIAMPA, António da Costa. Identidade. In: LANE, Silvia, CODO, Wanderiey (Oigs.). Psicologia social: o homem em movimento. São Paulo: Brasiliense, 1984. p.59-75.

GRAMSCI. Os intelectuais e a organização da cultura.l.oà. Rio de Janeiro: Civilização Brasileira, 1978.

HALLIDAY, M.A.K. Explorations in the functions of language. London: EdwardArnold, 1973. p.9-21. 
LABOV, W. The logic of nonstandard English. In: GIGLIOLI, P.P. (Org.). Language and social context. Harmondsworth: Penguin, 1972. p. 179-215.

MILROY, L. Language and social neworks. Oxford: Basil Blackewell, 1980.

PORZIG, W. El mundo marvilloso dei lenguage, problemas, métodos resultados de I'linguística moderna. Trad. por Abelardo Moralego. Madrid: Gredos, 1970.

REGO, L.L.B. A escrita da estória por crianças: as implicações pedagógicas do uso de um registro linguístico. Revista DELTA, São Paulo, v.2, n.2, 1984.

SAMPAIO, M.C.H., SPINILlO, A.G. Por uma nova concepção de alfabetização: relatório técnico final. Recife: Centro Josué de Castro de Estudos e Pesquisaas; Brasília: Conselho Nacional de Pesquisa, 1986. 2v.

SAMPAIO, M.C.H., SPINILLO, AG., CHAVES, M.F. O uso do registro narrativo literário nas estórias orais de alunos de $\mathrm{I}^{\mathrm{a}}$ série. Educação em Questão, v.4, n.1, 1990.

. Compreensão de narrativas: inferências pragmático-culturais. Caderno de Pesquisas Sociais, v.2, n.2, p.529-542, jul./dez. 1987.

SAUSSURE, F. de. Curso de linguística geral.6.ed. Trad. por A. Chelini, J.P. Paes e I. Blikstein. São Paulo: Cultrix, 1982. Tradução de: Cours de Linguistique Genérale.

Recebido em 15 de abril de 1993

Maria Cristina Hennes Sampaio, mestre em Linguística pela Pontifícia Universidade Católica do Rio Grande do Sul (PUC/RS), é professoraassistente do Departamento de Letras Clássicas e Vernáculas da Universidade Federal da Paraíba (UFPB). 
Rosilda Arruda Ferreira, mestre em Sociologia pela Universidade Federal de Pernambuco (UFPE), é professora-assistente do Departamento de Fundamentos Sócio-Filosóficos da Educação do Centro de Educação da referida universidade.

The purpose of this study was to analyse the way pedagogical practice, regarding teaching and learning ofMother Tongue, is being conducted at public schools, considering children 's sociolinguistic diversity. In order (o reach this aim, seventy-five first year grade teachers of the public school system of Recife have been investigated. A tipology involving conceptual and action palterns, correlated to several social variables, has been established. The process has also been investigated through a network study adapted from Milroy (1980). Five different conceptual categories have been observed, ali of them inserted into a only pedagogical action category. It was concluded that most of the teachers presented a profile whose conceptual traces are strongly related to linguistic and cultural values of the dominant classes. From the correlation between the five conceptual categories and the only action category observed, it was concluded a lack of articulation between theory and practice, particularly regarding categories $I V$ and $V$, whose differencesfrom the remaining categories may be identified by Identification traces with the linguistic and cultural values of popular classes. It was also concluded that there is no relation between teacher 's insertion in his working community (of popular class) and his links to this class with a approximation or a distancing of linguistic and cultural values of popular classes. The results contributedfor a better comprehension ofsign dialetic relation as a effect of social structures, as well as in as much social identity, shaped (or partially shaped) by the dominant ideology, has determinated teacher 's conceptions and pedagogical practice. 
// s 'agit d 'une étude sur la manière dont la pratique pédagogique de l'enseignement-apprentissage de la Langue Maternelle, est menée dans l'école publique, tout en considérant la dimensité socio-linguistique de sonpublic. On a éíudié un échantillon d'à peu prés 75 enseignants de la $l^{e r e}$ classe de l'enseignementprimaire des écolespubliques de Recife. On a établi une typologie de 5 conceptions et des actions d'enseignementapprentissage de la Langue Maternelle, en rapport avec plusieurs variables sociales. Le processus a été, enplus, étudié à travers une "étude de réseaux" (Milroy, 1980). On a observe 5 groupes de concepts, qui présententdesdiffèrencesconceptuelles, mais qui, d'aprèsnotre typologie, represente une même et unique catégorie d'action pédagogique. On a conclui que la grande majorité des enseignants présentent un "profil" dont les traits concepíuels sont ceux des valeurs linguistiques et adiurelles de la classe dominante. En prennant le rapport entre les 5 caíégories "conceptuelles " et la seule catégorie d' "action ", on a conclu de l'absence d'un rapport plus solide entre la théorie et la pratique, en spécial, en ce qui concerne les groupes concepíuels IV et $V$, qui, différemmení des auíres groups, préseníeníune identification plus proche des valeurs linguisíiques et culturelles des classes populaires. En outre, on a conclu que Vintégration de l'enseignaní dans la communauté ou il travaille (les classes populaires), et même son origine "populaire", on pressenl guère une relaíion directe avec la proximiíé ou l'éloignement des valeurs linguistiques et culturelles des classes dominantes ou populaires. Les resultais de la recherche ont ouvert la possibilite d'une comprêhension des rapports dialectiques du "signe", en tant que resultai des structures sociales. On voit, d'ailleurs, dans que lie mesure Videntitè sociale, influencée (on paríiellement influencée) par l'ideólogie dominante, conditionne les concepíions eíl 'acíion pédagogique des enseignants. En outre, la confrontation entre les conceptions et l 'action, montre bien la dificulié d'une arliculaiion enlre la íhéorie eí la pratique, et pourlant, tout cela offre la possibilite d'une réflexion sur les conditions de son "dépassemení". 
El estúdio aborda el modo como la práctica pedagógica de la ensenãnza de la Lengua Pátria está siendo trabajada en la escuela pública, contemplando la diversidad deiproceso tambiénfue investigado através de un estúdio de escuelas adaptado de Milroy, 1980. Fueron observadas cinco categorias conceptuales que presentan diferencias conceptuales y que inserense solamente en categoria única de acción pedagógica. Concluese que lagran mayoria de los profe sores presentan un perfil cujos rasgos conceptuales quedan fuertemente voltados a los valores liguísticos/culturales de las clases dominantes. De la correlación entre las cinco categorias conceptuales y la categoria única de acción concluese por la falta de aríiculación entre teoria y práctica, sobre todo en las categorias conceptuales $I V$ y $V$ que se diferencian de las otras porque presentam trazos de identif/cación con los valores linguisticos culturales de las clases populares. Concluese también que la inserción dei profesor en la comunidad de írabajo (de clase popular) y su vinculación a la misma clase no presenta una relación directa de proximidad o lejania de los valores linguísticos culturales de las clases dominantes o populares. Los resultados han possibilitado la comprensión de la relación dialéctica dei signo mientras sea consecuencia de las esírucíuras sociales y también los resultados posibilitaran comprender hasta quepunto la identidad social modelada (o parcialmente modelada) por la ideologia dominante, condiciono las concepciones y la acción pedagógica de los profe sores. Adernas, la contraposición de ellas posibilitó la identificación de la dificultad de aríiculación entre teoria y práctica y la reflexión sobre las posibilidades de su superación. 